\title{
INFORMATION TECHNOLOGIES AS A MEANS OF IMPROVING THE EFFICIENCY OF THE STATE AND PUBLIC AFFAIRS MANAGEMENT
}

\author{
Sergey G. Vasilevich \\ Belarusian State University, Minsk, Belarus
}

\begin{abstract}
Introduction: the paper examines the impact of information technologies on the management of state and public affairs. It is emphasized that these technologies significantly change the nature of the relationship between a person and the state, contribute to their democratization, as well as the optimization of the system and the activities of the state bodies. Drawing attention to the positive side of the digital transformation of public relations, at the same time, it is noted that information technologies, as well as the technical developments based on them, narrow the scope of private space. In this regard, it is important to find a balance between public and private interests. Several proposals are made to improve the legal regulation and practice in this area. Introduction: in the modern period, more and more attention is paid to the digital transformation of public relations. The development of information technologies creates new conditions for the dynamic development of the state and law, the adoption of effective management decisions. Purpose: to evaluate the possibilities of using information technologies in the field of public administration, to make suggestions on possible improvements in the legislation and practice. Methods: the methods of systematicity, analysis, and comparative law method are used. Results: based on the analysis of trends in the legal regulation in using information technologies in the economic, social, and political spheres some proposals for improving the legislation and practice are made. Conclusions: the introduction of IT in the public space optimizes and integrates diverse processes and procedures, creating a new paradigm, which ultimately improves the quality of public services and expands communication channels, introduces people to the process of making political decisions. Regarding the digital transformation in the field of human rights and freedoms, one should be guided by the principle: the rights that a person has offline should also be protected online (on the Internet).
\end{abstract}

Key words: digitalization, public administration, information technologies, social rating, society.

Citation. Vasilevich S.G. Information Technologies As a Means of Improving the Efficiency of the State and Public Affairs Management. Legal Concept = Pravovaya paradigma, 2021, vol. 20, no. 3, pp. 76-81. (in Russian). DOI: https://doi.org/10.15688/lc.jvolsu.2021.3.12

\section{ИНФОРМАЦИОННЫЕ ТЕХНОЛОГИИ \\ КАК СРЕДСТВО ПОВЫШЕНИЯ ЭФФЕКТИВНОСТИ УПРАВЛЕНИЯ ГОСУДАРСТВЕННЫМИ И ОБЩЕСТВЕННЫМИ ДЕЛАМИ}

Белорусский государственный университет, г. Минск, Беларусь

Введение: в статье исследуется влияние информационных технологий на осуществление управления государственными и общественными делами. Подчеркивается, что указанные технологии существенно меняют характер взаимоотношений человека и государства, способствуют их демократизации, а также оптимизации системы и деятельности государственных органов. Обращая внимание на позитивную сторону цифровой трансформации общественных отношений, в то же время мы отмечаем, что информационные технологии, а также технические разработки на их основе сужают сферу частного пространства. В этой связи важно 
найти баланс между публичными и частными интересами. Вносится ряд предложений по совершенствованию правового регулирования и практики в указанной сфере. В современный период все большее внимание уделяется цифровой трансформации общественных отношений. Развитие информационных технологий создает новые условия для динамичного развития государства и права, принятия эффективных управленческих решений. Цель: оценить возможности использования информационных технологий в сфере государственного управления, высказать предложения по возможному совершенствованию законодательства и практики. Методы: использованы методы системности, анализа и сравнительно-правовой метод. Результаты: на основе анализа тенденций правового регулирования в области использования информационных технологий в экономической, социальной и политической сферах, по итогам которого высказаны предложения по совершенствованию законодательства и практики. Выводы: внедрение информационных технологий в публичном пространстве оптимизирует и интегрирует разноплановые процессы и процедуры, создавая новую парадигму, что в итоге улучшает качество предоставления государственных услуг и расширяет каналы коммуникации, приобщает людей к процессу принятия политических решений. Касаясь цифровой трансформации в области прав и свобод человека, следует руководствоваться принципом: права, которые человек имеет офлайн, должны защищаться и онлайн (в Интернете).

Ключевые слова: цифровизация, государственное управление, информационные технологии, социальный рейтинг, общество.

Цитирование. Василевич С. Г. Информационные технологии как средство повышения эффективности управления государственными и общественными делами // Legal Concept = Правовая парадигма. - 2021. T. 20, № 3. - C. 76-81. - DOI: https://doi.org/10.15688/lc.jvolsu.2021.3.12

\section{Введение}

Информационные технологии (далее ИТ) играют важную роль в жизни современного общества. Активно развиваясь, они проникают во все сферы жизнедеятельности людей: торговля и оплата, банковский сектор, образование и наука, работа и отдых, а также сфера оказания государственных услуг и государственного управления с целью принятия эффективных управленческих решений - все это еще буквально 15-20 лет назад невозможно было представить в онлайн-формате. В наши дни ИТ так глубоко проникли в повседневную жизнь, что большинство людей не представляет себе своего существования без современных средств коммуникации и сервиса. В этой связи ИТ, доступ к информации, оказание услуг онлайн и т. д. нуждаются в скорейшей и качественной правовой регламентации с целью как защиты прав пользователей услуг, операторов, получающих и обрабатывающих информацию, так и возложения на них определенных обязанностей.

\section{Информационные технологии в жизни государства и общества на современном этапе}

Для современных реалий характерно динамичное и постоянно расширяющееся внедрение ИТ в основные сферы человеческой деятельности. Они охватывают своим влиянием и юридическую сферу, для которой актуальны такие направления, как нормотворчество и правоприменение. Цифровизация в области юридической деятельности способствует принятию обоснованных и более точных решений, быстрому поиску сведений, их анализу и прогнозу последствий [8]. Цифровая трансформация становится неотъемлемым фактором эффективности государственного управления, оптимизирует систему властных отношений, деятельность государственных институтов [2, с. 26]. Ускоренный темп использования информационно-коммуникационных технологий характерен для последних трех десятилетий, хотя об информационном обществе футурологи начали заявлять еще в середине прошлого века. Воздействие ИТ направлено не только на государственные структуры, но и на субъекты гражданского общества, формирование современного образа жизни людей. Развитие информационного общества уже стало основополагающим направлением общественной динамики.

$\mathrm{OOH}$ рассматривает электронное правительство в качестве характеристики нового уровня взаимодействия между ветвями власти, между государством и человеком, а также обществом. Внедрение ИТ в публичном пространстве оптимизирует и интегрирует разноплановые процессы и процедуры, созда- 


\section{ТЕОРИЯ И ПРАКТИКА ГОСУДАРСТВЕННО-ПРАВОВОГО РАЗВИТИЯ}

вая новую парадигму, что в итоге улучшает качество предоставления государственных услуг и расширяет каналы коммуникации, приобщает людей к процессу принятия политических решений [12].

Правильность выбранного вектора развития в контексте внедрения ИТ подтверждается зарубежным опытом, например, Эстонии, которая добилась наилучших успехов в данной области среди всех постсоветских республик. ИТ существенно экономят время. Так, благодаря их внедрению в Австрии в среднем экономится до двух часов при поиске информации по интересующему вопросу, действующий в США правительственный портал обеспечивает доступ к 20 тыс. интернетсайтам государственных органов, он бесплатен для пользователей [2, с. 27].

Таким образом, оперативный и удобный доступ к информации создает более комфортные условия для жизни людей. Нынешние достижения основываются на фундаментальных трудах ученых, которые занимались исследованиями в области кибернетики и информатики, например, исследование Н. Винера [5, c. 33-34], показавшее органическую связь информации с теорией управления. В нынешних условиях высказывается много суждений в пользу так называемого программируемого общества.

Российский ученый М.M. Рассолов, характеризуя сущность информационной системы в области, связывал ее с процессом труда. Обращаясь к повседневной деятельности работников правоохранительных органов, предметом труда которых является разнообразная социально-правовая информация, он подчеркивал значение информации, облекаемой в необходимые формы с целью принятия управленческих решений [10, с. 19].

По справедливому замечанию И.Ю. Богдановской, право человека на информацию динамично развивалось: сначала оно было более ограниченным в период становления конституционной государственности, затем в условиях формирования информационного общества акцент смещается в сторону возникновения у государства обязательств по дополнительному регулированию механизма доступности информации, это изменило содержание права на информацию в целом [3, с. 5].
Использование ИТ было нацелено на дебюрократизацию отношений между государством и человеком, расширение прав и свобод. Мы разделяем позицию Л.В. Журавлевой, которая считает, что доступ к населения к ИТ становится ускорителем модернизации устоявшихся в течение прошлого века социальных моделей; новая ситуация предполагает использование более продуктивных средств для реализации управленческих функций и компетенций [6, с. 83].

Конечно, существует проблема готовности людей, организаций, органов управления изменить свой стиль жизни (управления), где коммуникационные и ИТ охватывают содержательную часть складывающихся отношений. Ведь человек, как субъект социума, включен во множество других его структур, а перестройка происходит под влиянием психологической, информационной, понятийной нагрузки. Это предполагает необходимость адаптации, создания для этого условий, развития компьютерной грамотности, соответствующих навыков, овладения необходимыми алгоритмами действий. Сложно возражать, что старшее поколение находится в боле трудном положении в части умения использовать современные технологии [9, с. 14]. Однако ничего не мешает государству, используя телевидение и интернет, давать необходимые бесплатные уроки для желающих расширить свои навыки в использовании указанных технологий.

В Российской Федерации давно сложилась информационная система оказания государственных услуг, обсуждения проектов нормативных правовых актов, база данных, касающихся учета автотранспорта и иного имущества, осуществления сделок с ним. ИТ содействуют развитию электронной демократии, коллаборативному управлению граждан делами государства и общества. Беларусь также, используя собственный, российский и иной зарубежный опыт, активно развивает информационное общество. В Беларуси еще в 2002 г. была утверждена программа «Электронная Беларусь». У нас функционирует государственная система правовой информации [4, c. 299]. Позитивные отклики специалистов получил изданный Президентом Беларуси в декабре 2017 г. декрет № 8 «О развитии цифро- 
вой экономики», которым предусмотрено создание условий для использования в экономике технологии реестра блоков транзакций (блокчейн) и иных высоких технологий. В декрете № 8 установлен ряд иных новаций.

ИТ внедряются не только в систему представительной, исполнительной власти, но и в сферу деятельности надзорных органов. Так, например, в НИИ для решения проблемы укрепления законности и правопорядка при Генеральной прокуратуре Российской Федерации была разработана Концепция создания автоматизированной системы информационного обеспечения органов прокуратуры Российской Федерации, что позволило создать в Российской Федерации единую автоматизированную информационную среду. Благодаря этому обеспечиваются потребности в области информации системы органов прокуратуры всех уровней. Усиливается оперативность надзора со стороны прокуратуры. Создание аналогичной автоматизированной информационной системы происходит и у нас. Органам прокуратуры Беларуси обеспечен доступ к автоматизированным системам иных ведомств. Надзорная функция станет еще более эффективной, когда будет завершено создание интегрированной с судами системы.

Полагаем, что и в Беларуси, и в Российской Федерации уделяется внимание организации надлежащей работы с обращениями граждан, включая электронные. Создаваемые в государственных органах информационные платформы позволяют органам прокуратуры при необходимости осуществлять надзор по своевременному выявлению нарушений. Внедрение новых механизмов и технологий направлено также на противодействие коррупции, в частности, в сфере государственных закупок, отвода земельных участков, выдачи различного рода документов и др. [7].

Укреплению законности, обеспечению оперативного рассмотрения обращений граждан и юридических лиц, снижению их потока могло бы способствовать создание такого порядка, в соответствии с которым на сайтах министерств, государственных комитетов, местных представительных и исполнительных органов размещались бы ответы на типичные вопросы. Это своего рода упреждающее консультирование может экономить время и ре- сурсы. В перспективе следовало бы заняться созданием банка данных решений органов исполнительной власти, являющихся административными прецедентами. Конечно, пока отношение к прецедентам (судебным и административным) в наших странах неоднозначное. Об этом идут споры и между учеными. Признавая подзаконный статус прецедента, автор данной статьи убежден в его полезности с точки зрения обеспечения единообразного применения актов законодательства.

Информационной открытости принятия решений органами публичной власти может способствовать размещение на их официальных сайтах сведений о планах работы на год и их выполнении. Общественный контроль в данном случае очень важен [11, с. 157].

ИТ, а также технические разработки на их основе сужают сферу частного пространства. Это можно наблюдать в связи с широким использованием камер видеонаблюдения в местах массового проживания людей. Использование, например, дронов позволяет наблюдать за частной жизнью людей, их пребыванием на территории, где размещены их дома, постройки. Право на информацию и право частной жизни напрямую сейчас связаны с правом на анонимность, правом быть оставленным в покое, правом на информационное самоопределение и др. Возникают вопросы о границах контроля за гражданами. В Китае уже создана система социального рейтинга, то есть система оценки поведения граждан (социальный рейтинг).

С 1 января 2021 г. каждому гражданину КНР предоставляется начальный рейтинг в 1000 баллов. Далее он растет либо уменьшается в зависимости от поведения человека. Лицу с высоким социальным рейтингом предоставляются льготы и другие преимущества от государства. Обладателю низкого рейтинга невозможно претендовать на достойную работу, в отношении него много ограничений (не дадут кредит, могут отказать в аренде велосипеда и т. п.). Как отмечают в СМИ, с помощью цифровых стимулов Китай пытается создать новое общество. В нем преимущество имеют законопослушные, вежливые и надежные люди [1]. Ученым еще предстоит основательно проанализировать основные составляющие концепции такой модели обще- 


\section{ТЕОРИЯ И ПРАКТИКА ГОСУДАРСТВЕННО-ПРАВОВОГО РАЗВИТИЯ}

ственного устройства, оценить наличие или отсутствие дискриминации, насколько здесь соотносятся частные и публичные интересы, основания и пределы ограничения прав и свобод, насколько правомерны цели ограничения. Выделяют три сферы, где важен социальный рейтинг: государственная (уплата налогов, погашение кредитов); общественная (поведение в обществе, включая соблюдение правил дорожного движения, соблюдение норм рождаемости, честность в работе и образовании); поведение в сети (культура общения с пользователями, достоверность размещаемой информации и др.). Все это сводится в единую базу [1].

Конечно, опыт Китая впечатляет, для наших государств (Российской Федерации и Беларуси) он необычен, но изучить его полезно.

\section{Выводы}

В заключение отметим, что использование ИТ позволяет дебюрократизировать широкий спектр отношений между государством и обществом, способствует расширению прав и свобод человека, укреплению законности и правопорядка. Появляется новый горизонт для динамичного развития нормотворческой и правоприменительной деятельности.

\section{СПИСОК ЛИТЕРАТУРЫ}

1. Акиньшин, В. Кредит на свободу: как изменится общество в Китае после запуска системы оценки поведения граждан / В. Акиньшин. - Электрон. текстовые дан. - Режим доступа: https:// tvzvezda.ru/news/2021117212-qp6hd.html (дата обращения: 04.04.2021). - Загл. с экрана.

2. Алферова, Е. В. Информационные технологии в государственном управлении: новые возможности / Е. В. Алферова // Информационные технологии: Инновации в государственном управлении : сб. науч. тр. / отв. ред. Е. В. Алферова, И. Л. Бачило. М. : ИНИОН, 2020.- С. 24-46.

3. Богдановская, И. Ю. Право на доступ к информации. Доступ к открытой информации / И. Ю. Богдановская. - М. : Юстицинформ, 2009. - 344 с.

4. Василевич, Г. А. Конституция. Человек. Государство : материалы выступлений и статьи / Г. А. Василевич. - Минск : Веды. - 2006. - 312 с.

5. Винер, Н. Кибернетика / Н. Винер. - М. : Изд-во иностр. лит., 1958. -252 с.
6. Журавлева, Л. В. Информационные технологии в современном мире / Л. В. Журавлева // Право и информатизация общества : сб. науч. тр. / РАН ИНИОН, Центр социальных науч.-информ. исслед. - М., 2002. - С. 75-88.

7. Информационные технологии в работе законодательных органов, прокуратуры. - Электрон. текстовые дан. - Режим доступа: https://studfiles.net /preview/2848240/page:6/ (дата обращения: 11.04.2021). - Загл. с экрана.

8. Информационные технологии в юридической деятельности. - Электрон. текстовые дан. - Режим доступа: http://bizescort.ru/about/news/ informacionnye-tehnologii-v-uridicheskoydeyatelnosti/ (дата обращения: 15.04.2021). - Загл. с экрана.

9. Информационные технологии: инновации в государственном управлении : сб. науч. тр. / отв. ред. Е. В. Алферова, И. Л. Бачило. - М. : РАН; ИГП. Сектор информ. права; Инион. Центр социал. науч.информ. исслед. Отдел правоведения, 2010. - 238 с.

10. Рассолов, М. М. Правовая информатика и управление в сфере предпринимательства : учеб. пособие / М. М. Рассолов, В. Д. Элькин, И. М. Рассолов. - М. : Юристь, 1996. - 480 с.

11. Талапина, Э. В. Государственное управление в информационном обществе (правовой аспект) / Э. В. Талапина. - М. : Юриспруденция, 2015. - 192 с.

12. United Nations E-Government Survey 2014: E-Government for the Future We Want. Electronic text data. - Mode of access: https:// publicadministration.un.org/egovkb/Portals/egovkb/ Documents/un/2014-Survey/E-Gov Complete Survey-2014.pdf(date of access: 11.01.2021). - Title from screen.

\section{REFERENCES}

1. Akinshin V. Kredit na svobodu: kak izmenitsya obshestvo $v$ Kitae posle zapuska sistemy ocenki povedeniya grazhdan [Credit for Freedom: How Society Will Change in China After the Launch of the System for Assessing the Behavior of Citizens]. URL: https://tvzvezda.ru/news/2021117212-qp6hd.html (accessed 4 April 2021).

2. Alferova E.V. Informacionnye tehnologii $\mathrm{v}$ gosudarstvennom upravlenii: novye vozmozhnosti [Information Technologies in Public Administration: New Opportunities]. Informacionnye tehnologii: Innovacii v gosudarstvennom upravlenii: sb. nauch. tr. [Information Technologies: Innovations in Public Administration. Collection of Scientific Papers]. Moscow, Yustitsinform Publ., 2010, pp. 24-46.

3. Bogdanovskaya I.Yu. Pravo na dostup $k$ informacii. Dostup k otkrytoj informacii [The Right to 
Access to Information. Access to Open Information]. Moscow, 2009. 344 p.

4. Vasilevich G.A. Konstituciya. Chelovek. Gosudarstvo. Materialy vystuplenij $i$ stati [Constitution. Person. State. Materials of Speeches and Articles]. Minsk, Vedy Publ., 2006. 312 p.

5. Viner N. Kibernetika [Kibernetik]. Moscow, Izdatelstvo inostrannoj literatury, 1958. 252 p.

6. Zhuravleva L.V. Informacionnye tehnologii v sovremennom mire [Information Technologies in the Modern World]. Pravo i informatizaciya obshestva: sb. nauch. tr. [Law and Informatization of Society. Collection of Scientific Papers]. Moscow, RAN INION, Centr socialnyh nauch.-inform. issled, 2002, pp. 75-88.

7. Informacionnye tehnologii $v$ rabote zakonodatelnyh organov, prokuratury [Information Technologies in the Work of Legislative Bodies and the Prosecutor's Office]. URL: https://studfiles.net/ preview/2848240/page:6/ (accessed 11 April 2021).

8. Informacionnye tehnologii v yuridicheskoj deyatelnosti [Information Technologies in Legal Activity]. URL: http://bizescort.ru/about/news/ informacionnye-tehnologii-v-uridicheskoydeyatelnosti/(accessed 15 April 2021).

9. Alferova E.V., Bachilo I.L. Informacionnye tehnologii: innovacii v gosudarstvennom upravlenii: sb. nauch. tr. [Information Technologies: Innovations in Public Administration: sb. nauch. tr.]. Moscow, INION RAN, 2010. 238 p.

10. Rassolov M.M., Elkin V.D., Rassolov I.M. Pravovaya informatika $i$ upravlenie $v$ sfere predprinimatelstva: ucheb. posobie [Legal Informatics and Management in the Field of Entrepreneurship: studies. manual]. Moscow, Yurist Publ., 1996. 480 p.

11. Talapina E.V. Gosudarstvennoe upravlenie v informacionnom obshestve (pravovoj aspekt) [State Management in the Information Society (Legal Aspect)]. Moscow, Yurisprudenciya Publ., 2015. 192 p.

12. United Nations E-Government Survey 2014: E-Government for the Future We Want. Department of Economic and Social Affairs. URL: https:// publicadministration.un.org/egovkb/Portals/egovkb/ Documents/un/2014-Survey/E-Gov_Complete_Survey2014.pdf(accessed 11 January 2021).

\section{Information About the Author}

Sergey G. Vasilevich, Candidate of Sciences (Jurisprudence), Associate Professor, Department of Constitutional Law, Faculty of Law, Belarusian State University, Prosp. Nezavisimosti, 4, 220030 Minsk, Belarus, sergey.workmail.135@gmail.com, https://orcid.org/0000-0003-1016-8782

\section{Информация об авторе}

Сергей Григорьевич Василевич, кандидат юридических наук, доцент кафедры конституционного права, Белорусский государственный университет, просп. Независимости, 4, 220030 г. Минск, Беларусь, sergey.workmail.135@gmail.com, https://orcid.org/0000-0003-1016-8782 